Terbit online pada laman web jurnal: http://journal.isas.or.id/index.php/JASENS

JOURNAL OF APPLIED SMART ELECTRICAL
NETWORK AND SYSTEMS (JASENS)
ISAS

\title{
Antarmuka Mikrokontroller IoT (ESP32) Dengan USB Host max3421e
}

\author{
Rieke Adriati Wijayanti ${ }^{1}$, Ahmad Wilda Yulianto ${ }^{2}$, Dianthy Marya ${ }^{3}$, M. Syirajuddin S. ${ }^{4}$, Nurul Hidayati ${ }^{5}$ \\ 1,2,3,4,5 Jurusan Teknik Elektro, Politeknik Negeri Malang \\ ${ }^{1}$ riekeaw@polinema.ac.id*,2ahmadwildan@polinema.ac.id, ${ }^{3}$ dianthy@polinema.ac.id, ${ }^{4}$ syirajuddin@polinema.ac.id, \\ ${ }^{5}$ nurulhid8@polinema.ac.id,
}

\begin{abstract}
Electronic equipment made using old technology or electronic equipment in the entry level category has not been supported by networking equipment, so for the data communication process, the microcontroller requires interfacing facilities that are in accordance with the electronic equipment used, such as a USB port. With the microcontroller that supports IoT, it allows electronic equipment to communicate over the network. An IoT microcontroller such as the ESP32 is equipped with a WiFi feature but is not equipped with a USB controller feature, while the USB Host max3421e supports the communication process using SPI, so that those two microcontrollers can be used to form an interface using the SPI bus. This interface can be applied to electronic equipment with old technology and entry level electronic equipment for wireless communication. For the needs of making an interface between the ESP32 and max3421e, a software was developed by analyzing the SPI features of the ESP32 and the USB protocol according to the USB device state diagram. The results obtained are the handshake process between systems developed with USB devices in the Low-Speed and Full-Speed categories such as printers, flashdisk, bluetooth mouse and external hard disk, and the device descriptor data of each device tested can be read properly.
\end{abstract}

Keywords: interface, microcontroller ESP32, USB Host max3421e, SPI, handshake

\begin{abstract}
Abstrak
Peralatan elektronik yang dibuat menggunakan teknologi lama maupun peralatan elektronik dengan kategori entry level belum didukung oleh peralatan networking, sehingga untuk proses komunikasi data, mikrokontroller memerlukan fasilitas interfacing yang sesuai dengan peralatan elektronik yang digunakan, seperti USB port. Dengan adanya mikrokontroller yang mendukung IoT, memungkinkan peralatan elektronik tersebut untuk melakukan komunikasi melalui network. Mikrokontroller IoT seperti ESP32 telah dilengkapi dengan fitur WiFi namun tidak dilengkapi dengan fitur USB controller, sedangkan USB Host max3421e mendukung proses komunikasi menggunakan SPI, sehingga kedua mikrokontroller tersebut dapat dimanfaatkan untuk membentuk antarmuka menggunakan SPI bus. Antarmuka tersebut dapat diaplikasikan pada peralatan elektronik dengan teknologi lama dan peralatan elektronik entry level untuk melakukan komunikasi secara wireless. Untuk kebutuhan pembuatan antarmuka antara ESP32 dan max3421e, dikembangkan software dengan cara menganalisis fitur SPI dari ESP32 dan protokol USB sesuai dengan device state diagram dari USB. Hasil yang didapatkan adalah proses handshake antara sistem yang dikembangkan dengan device USB dengan kategori Low-Speed dan Full-Speed seperti printer, flashdisk, bluetooth mouse dan external hard disk dapat berjalan dengan baik, serta data device descriptor dari setiap device yang diuji dapat dibaca dengan benar.
\end{abstract}

Kata kunci: antarmuka, mikrokontroller ESP32, USB Host max3421e, SPI, handshake

Diterima Redaksi : 01-12-2020 | Selesai Revisi : 18-12-2020 | Diterbitkan Online : 31-12-2020

\section{Pendahuluan}

Peralatan elektronik terkini sangat lekat dengan fasilitas networking seperti WiFi sehingga proses komunikasinya dapat dilakukan melalui WiFi. Sedangkan peralatan elektronik yang dibuat menggunakan teknologi lama Mikrokontroller IoT seperti ESP32 memiliki fitur WiFi maupun peralatan elektronik dengan kategori entry level tetapi tidak memiliki fitur USB controller yang belum didukung oleh peralatan networking, sehingga terintegrasi dalam 1 chip. Sedangkan USB Host untuk proses komunikasi data, mikrokontroller max3421e mendukung proses komunikasi memerlukan fasilitas interfacing yang sesuai dengan menggunakan SPI (Serial Peripheral Interface), peralatan elektronik yang digunakan, seperti USB port. sehingga kedua mikrokontroller tersebut dapat saling Namun dengan adanya mikrokontroller yang mendukung IoT, memungkinkan peralatan elektronik dengan teknologi lama maupun peralatan elektronik dengan kategori entry level untuk melakukan komunikasi melalui network [1]. 
dimanfaatkan untuk proses antarmuka menggunakan SPI bus [2].

Pada penelitian terdahulu yang telah dilakukan, USB Host max3421e dihubungkan dengan modul mikrokontroller Arduino yang memiliki fasilitas terbatas menggunakan SPI bus. Kemudian komunikasi dengan USB device dilakukan secara wired. Konfigurasi tersebut digunakan untuk menerima sinyal kontrol dan sensorik melalui USB port dari pergerakan quadcopter untuk kemudian dijalankan dari smartphone [3] dan juga diaplikasikan pada sistem penginderaan optic portable untuk mendeteksi sepktrum fluoresensi secara cepat [4]. Pada penelitian lain mengenai pengambilan gambar pada kamera DSLR, USB Host max3421e juga diaplikasikan sebagai perangkat yang menjembatani komunikasi antara mikrokontroller Arduino dengan kamera DSLR [5]. Selain itu, penelitian lain yang dilakukan oleh Novriadi adalah memanfaatkan mikrokontroller Arduino Mega yang dikombinasikan dengan USB Host max3421e untuk mengatur overhead crane baik secara wired maupun wireless dengan menggunakan Bluetooth [6].

Pada penelitian ini, akan dibangun sebuah sistem dengan menggunakan mikrokontroller ESP32 yang memiliki fasilitas networking (WiFi), 32 bit processor, RAM yang lebih besar dibandingkan Arduino [7][8] agar dapat
memfasilitasi aplikasi yang membutuhkan transaksi data yang lebih besar, seperti transfer data yang dikirimkan ke printer. Sehingga proses komunikasi yang selama ini hanya bisa dilakukan melalui wired (kabel USB), akan dapat dilakukan juga melalui wireless (WiFi). Namun pada penulisan jurnal ini masih dibatasi pada proses handshaking antara USB Host dengan device.

\section{Metode Penelitian} Penelitian ini diawali dengan merangkai mikrokontroller menggunakan 4 jalur, yaitu MOSI, MISO, SCK dan CS. ESP32 dan USB Host max3421e. USB Host max3421e Mode SPI yang digunakan adalah mode 0 atau full tersedia di pasar dalam bentuk modul yang kompatibel duplex, yaitu baik master dan slave bisa mengirim data dengan port modul Arduino. Untuk dapat terkoneksi pada saat yang sama melalui jalur MOSI dan MISO. dengan mikrokontroller ESP32, diperlukan routing yang Selama komunikasi ini, data ditransmisikan secara dirangkai di prototype board seperti terlihat pada bersamaan (bergeser secara serial ke bus MOSI / SDO) Gambar 1 berikut:

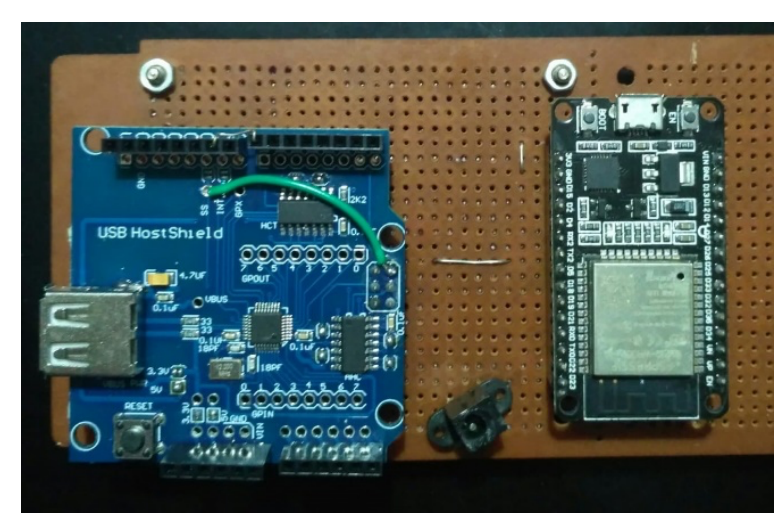

Gambar 1. Routing Mikrokontroller ESP32 dan USB Host max3421e
Setelah terkoneksi, dilakukan kegiatan pengecekan koneksi menggunakan Avometer. Kemudian dilanjutkan dengan pembuatan software yang akan ditanam di mikrokontroller ESP32. Pengembangan software ini menggunakan fasilitas yang sudah disediakan oleh pembuat mikrokontroller ESP32 yaitu ESP-IDF (IoT Development Framework.

\subsection{Blok Diagram Sistem}

Sistem yang akan dirancang terdiri atas mikrokontroller ESP32 dan juga USB Host max3421e digambarkan dalam blok diagram seperti pada Gambar 2 berikut:

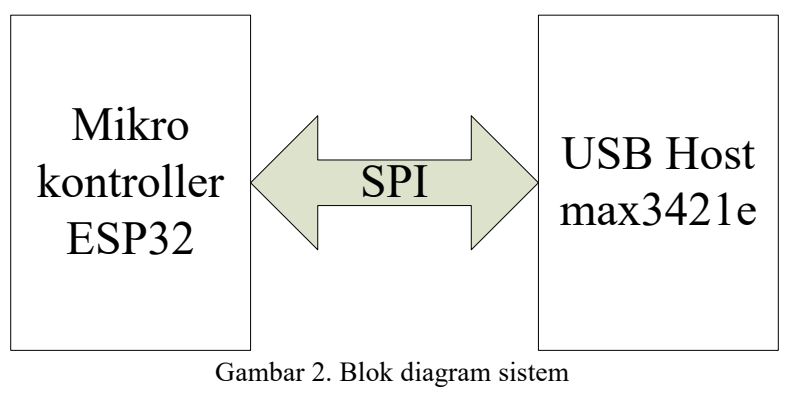

Mikrokontroller ESP32 dihubungkan dengan USB Host max3421e menggunakan SPI bus. Konfigurasi koneksi PIN yang dilakukan ditunjukkan dalam Tabel 1 berikut: Tabel 1.Tabel Konfigurasi koneksi PIN

\begin{tabular}{lcc}
\hline SPI Data & ESP32 Pin No & Max3421e Pin No \\
\hline MOSI & 23 & 4 \\
MISO & 19 & 1 \\
SCK & 18 & 3 \\
CS & 5 & 2 \\
\hline
\end{tabular}

dan diterima (data di bus (MISO / SDI) disampel atau dibaca) [9].

Untuk komunikasi SPI sendiri membutuhkan paling tidak tiga jalur, yakni MOSI, MISO, dan SCK. Melalui komunikasi ini data dapat saling dikirimkan baik antar mikrokontroler, maupun antara mikrokontroler dengan peripheral lainnya yang mendukung komunikasi dengan SPI [2].

\subsection{Pengembangan Software}

Pengembangan software memanfaatkan fasilitas ESPIDF. Pengembangan ini dilakukan dengan cara menganalisis fitur SPI dari mikrokontroller ESP32 dan protokol USB. Data dikirimkan dari peripheral ke USB Host untuk dianalisis dan diketahui unique address nya. Dengan mengetahui unique address yang terdapat pada 
peripheral, komunikasi data antara host bisa dilakukan. Untuk memastikan bahwa pembacaan device descriptor dari peripheral adalah benar, perlu ditambahkan command di dalam software, sehingga pengecekan data tersebut dapat dilakukan di PC melalui kabel USB.

Pengembangan software dilakukan berdasarkan Device State Diagram dari USB Device Framework [10] seperti yang ditampilkan dalam Gambar 3 berikut:
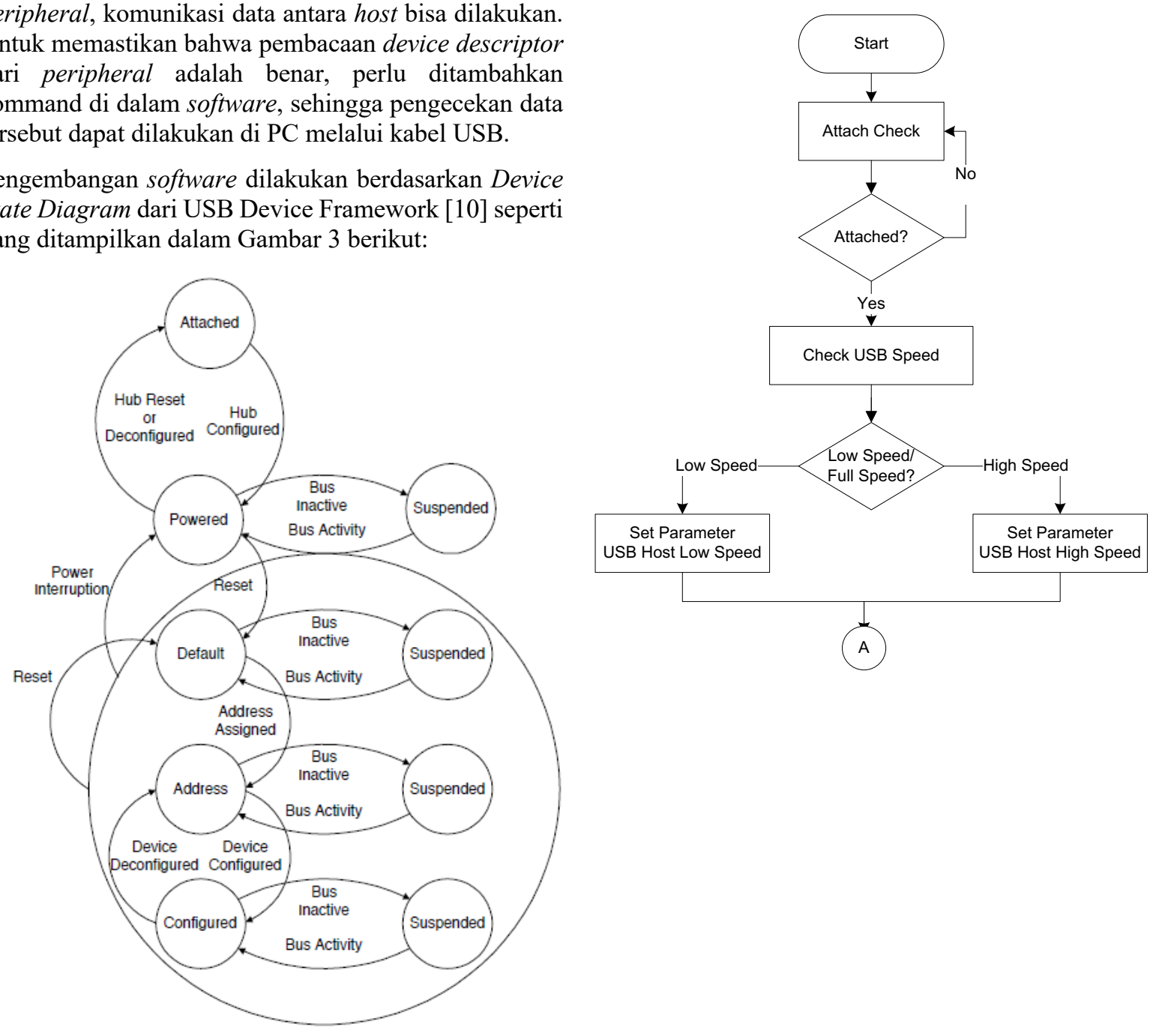

Gambar 3. Blok diagram sistem

Adapun diagram alir dari software yang dikembangkan dari Device State Diagram diatas ditunjukkan dalam Gambar 4 berikut: 


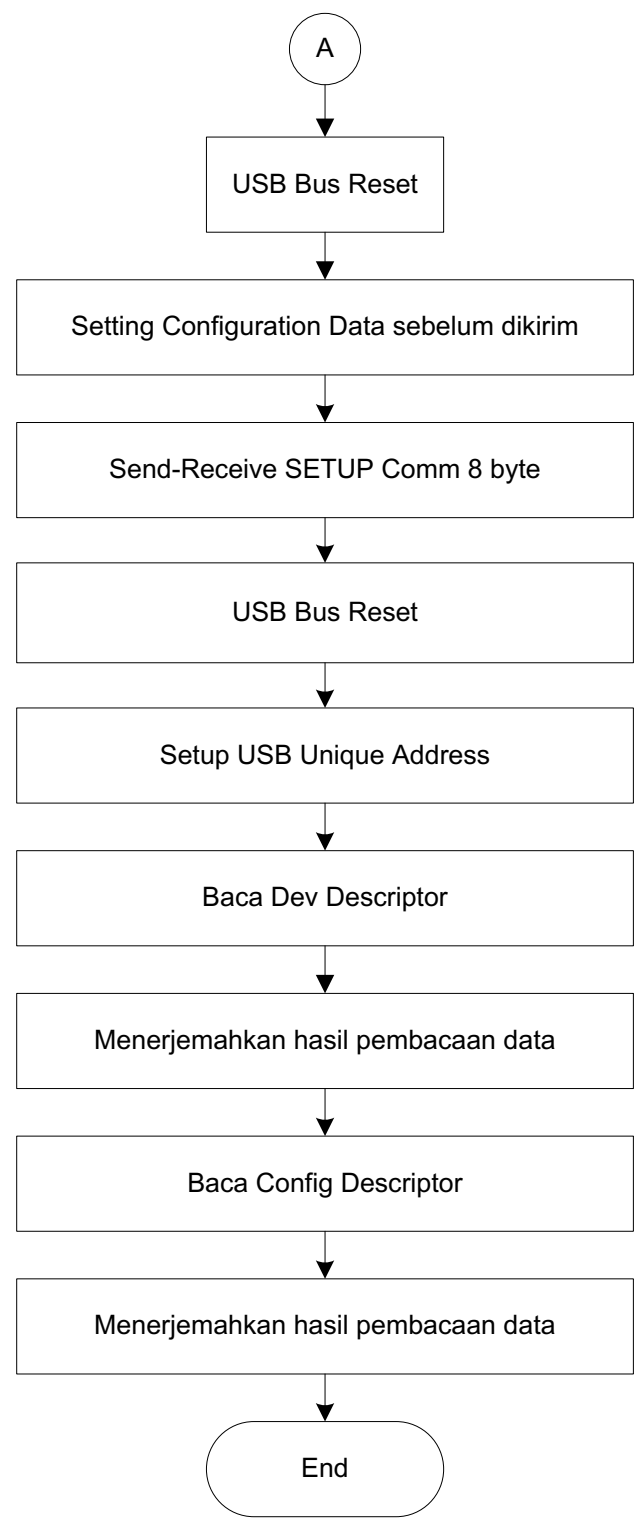

Gambar 4. Diagram alir software

Saat perangkat USB dipasang atau dilepas dari USB, host menggunakan proses yang disebut bus enumerasi untuk mengidentifikasi dan mengelola perubahan status perangkat yang diperlukan. Saat perangkat USB terhubung ke perangkat, langkah-langkah yang digambarkan pada Gambar 4 di atas dilakukan secara berurutan. Saat perangkat USB dilepas, hub kembali mengirimkan pemberitahuan ke host. Melepaskan perangkat berarti menonaktifkan port yang telah terpasang. Setelah menerima pemberitahuan pelepasan, host akan memperbarui informasi topologi lokalnya [10].

\subsection{Tahapan Pengujian}

Pengujian yang dilakukan pada penelitian ini adalah proses komunikasi menggunakan peralatan elektronik USB dengan kategori Low-Speed, Full-Speed dan HighSpeed yaitu printer Epson L210 yang tidak dilengkapi dengan fasilitas WiFi, flashdisk SanDisk, mouse bluetooth Logitech dan juga External Hard Disk Drive (HDD). Peralatan yang dikembangkan akan mencoba melakukan proses handshaking dengan semua peralatan elektronik tersebut sebagai objek USB peripheral. Adapun konfigurasi proses pengujian yang dilakukan ditampilkan pada Gambar 5 berikut:

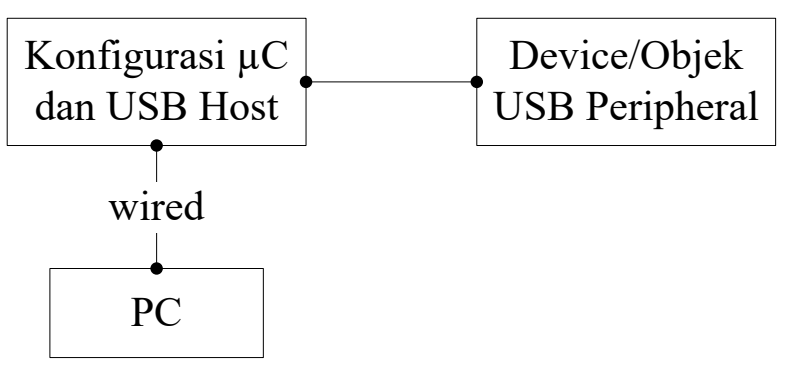

Gambar 5. Konfigurasi proses pengujian

\section{Hasil dan Pembahasan}

Pengujian terhadap sistem yang sedang dikembangkan dilakukan dengan menggunakan sistem operasi Linux untuk setiap device atau objek USB peripheral.

\subsection{Pengujian dengan Printer Epson L210}

Pengujian dilakukan dengan cara menghubungkan printer Epson L210 ke port USB Host max3421e dan PC ke mikrokontroller ESP32. Kemudian diambil data device descriptor yang dihasilkan dari koneksi tersebut. Adapun data device descriptor yang dihasilkan, ditampilkan pada Gambar 6 berikut:

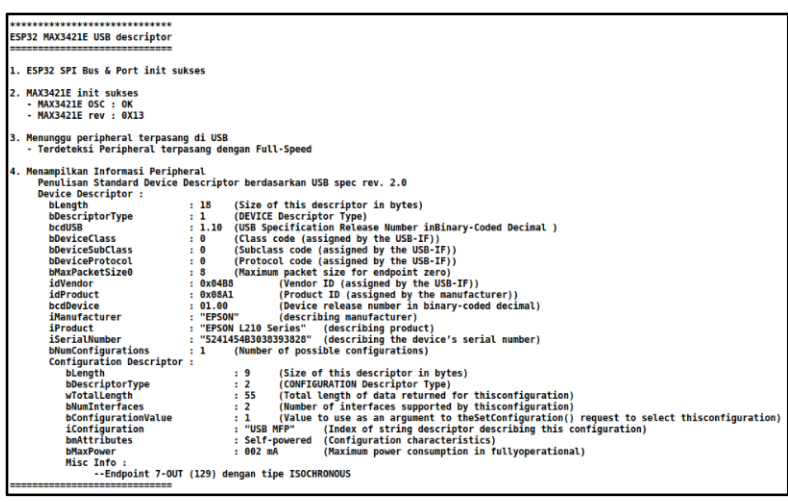

Gambar 6. Hasil device descriptor dari printer Epson L210

Dalam gambar tersebut, ditunjukkan iManufacturer $=$ EPSON dan iProduct $=$ EPSON L210 Series. Hal ini menunjukkan bahwa device descriptor yang dihasilkan dari software yang dikembangkan dapat berjalan dengan benar. Sebagai pembanding, device printer Epson langsung dihubungkan ke PC dan dilihat device descriptor dari PC. Hasil yang didapatkan ditampilkan dalam Gambar 7 berikut: 


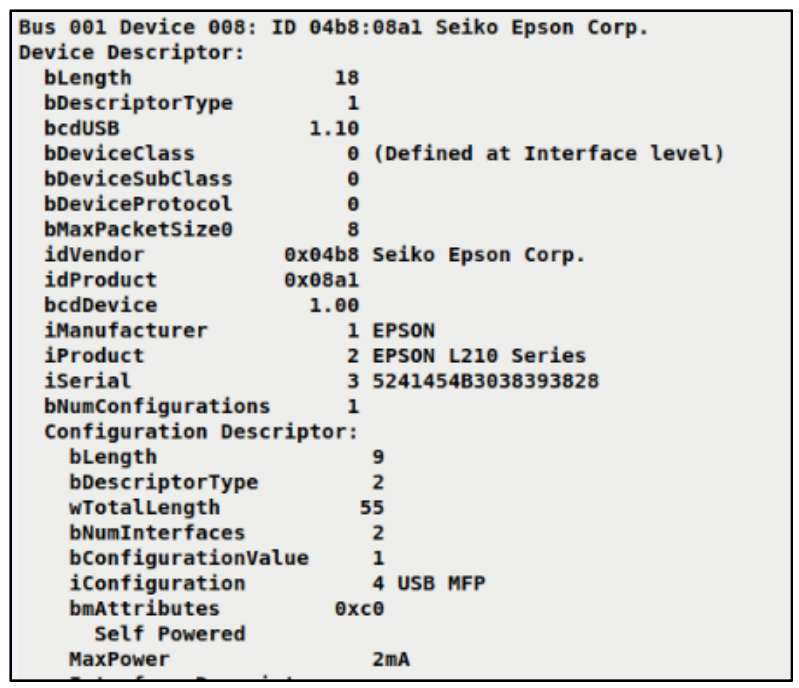

Gambar 7. Hasil device descriptor dari PC

Dari Gambar 7 di atas, dapat dilihat bahwa perangkat USB yang sedang terhubung di PC adalah printer EPSON L210 Series, ditunjukkan dengan iManufacturer $=$ EPSON dan iProduct $=$ EPSON L210 Series.

\subsection{Pengujian dengan Flashdisk SanDisk}

Dengan cara yang sama dengan pengujian menggunakan printer Epson di atas, didapatkan hasil pengujian menggunakan flashdisk SanDisk seperti yang ditunjukkan dalam Gambar 8 berikut:

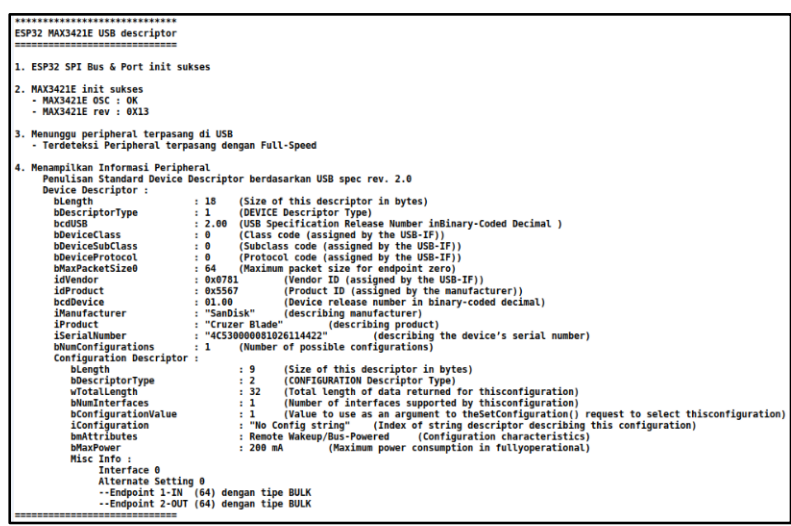

Gambar 8. Hasil device descriptor dari flashdisk SanDisk

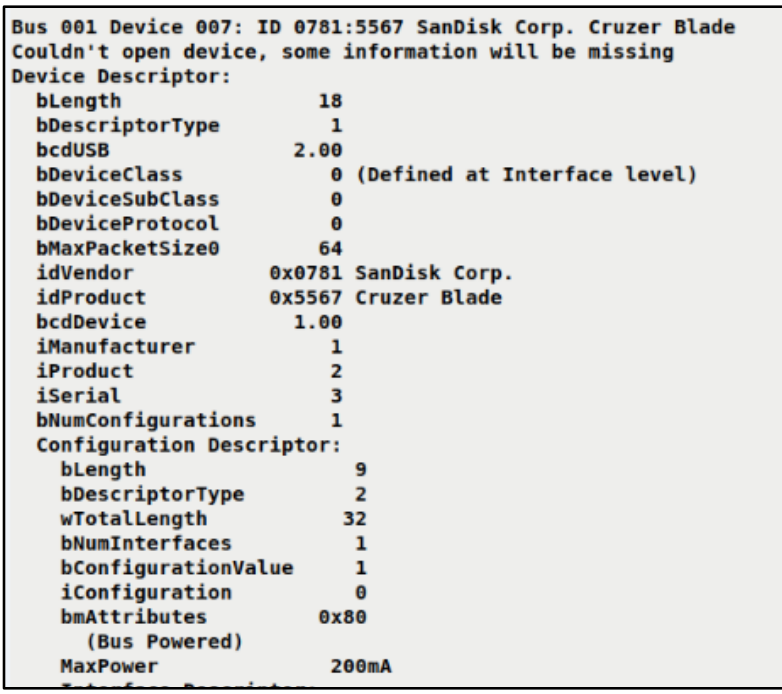

Gambar 9. Hasil device descriptor dari PC

\subsection{Pengujian dengan Mouse Bluetooth Logitech}

Dengan cara yang sama dengan pengujian menggunakan printer Epson dan flashdisk di atas, didapatkan hasil pengujian menggunakan mouse Bluetooth Logitech seperti yang ditunjukkan dalam Gambar 10 berikut:

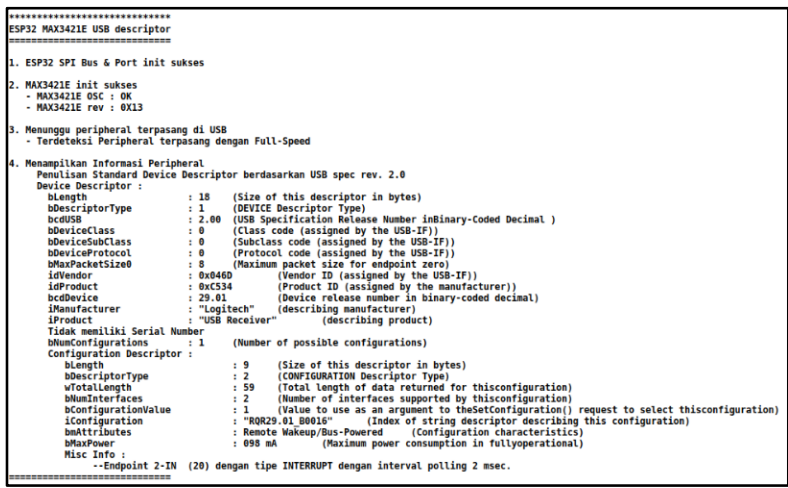

Gambar 10. Hasil device descriptor dari mouse bluetooth Logitech

Dalam gambar tersebut, ditunjukkan iManufacturer = Logitech dan iProduct $=$ USB Receiver. Hal ini menunjukkan bahwa device descriptor yang dihasilkan dari software yang dikembangkan dapat berjalan dengan benar. Sebagai pembanding, device mouse Bluetooth

Dalam gambar tersebut, ditunjukkan iManufacturer $=$ Logitech langsung dihubungkan ke PC dan dilihat device SanDisk dan iProduct $=$ Cruzer Blade. Hal ini descriptor dari PC. Hasil yang didapatkan ditampilkan menunjukkan bahwa device descriptor yang dihasilkan dalam Gambar 11 berikut:

dari software yang dikembangkan dapat berjalan dengan benar. Dalam Gambar 9 berikut ditunjukkan device descriptor berupa idVendor $=$ SanDisk Corp. dan idProduct $=$ Cruzer Blade yang diambil dari PC ketika device flashdisk SanDisk langsung dihubungkan ke PC. 


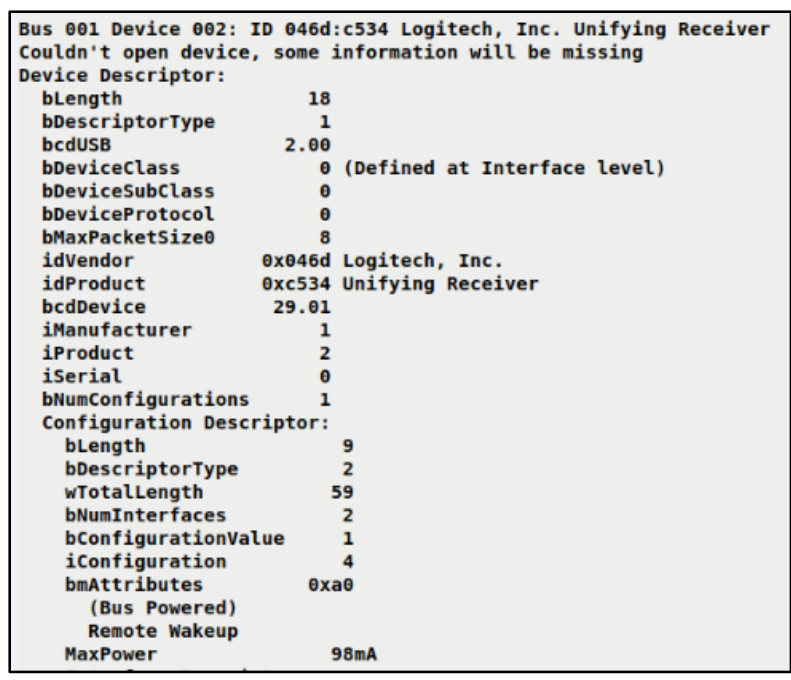

Gambar 11. Hasil device descriptor dari PC

Dari Gambar 11 di atas, ditunjukkan device descriptor berupa idVendor $=$ Logitech, Inc dan idProduct $=$ Unifying Receiver yang diambil dari PC ketika device mouse Bluetooth Logitech langsung dihubungkan ke PC.

3.4. Pengujian dengan External Hard Disk Drive (HDD) Logitec

Dengan cara pengujian yang sama dengan ketiga device di atas, didapatkan hasil pengujian device descriptor menggunakan external HDD Logitec berkapasitas 150 GB seperti yang ditunjukkan dalam Gambar 12 berikut ini:

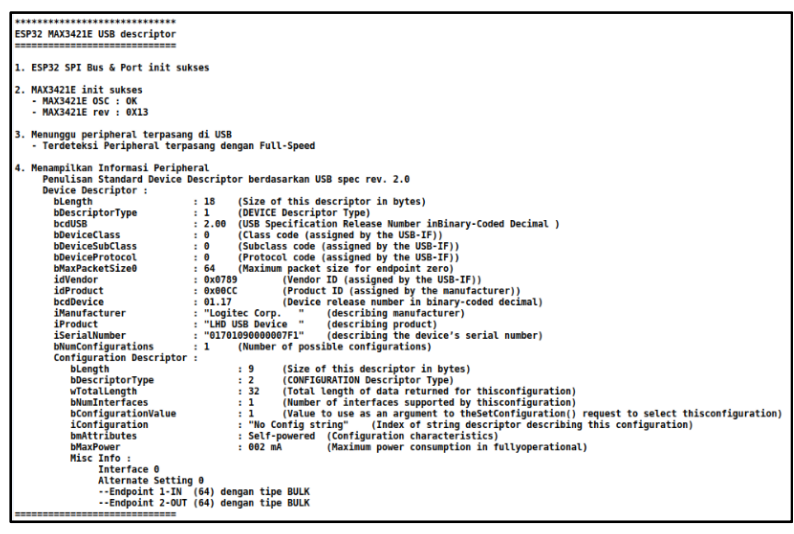

Gambar 12. Hasil device descriptor dari external HDD Logitec

\section{Kesimpulan}

Dari penelitian yang telah dilakukan, didapatkan hasil bahwa antarmuka antara mikrokontroller ESP32 dengan USB Host max3421e dapat dilakukan dengan baik. Proses handshake yang terjadi antara sistem dengan USB device berkategori Low-Speed dan Full-Speed seperti printer, flashdisk, Bluetooth mouse dan external harddisk dapat dilakukan dengan baik, serta data device descriptor dapat dibaca dengan benar. Pengembangan lebih lanjut dapat dilakukan agar sistem mampu melakukan proses handshake dengan USB device berkategori High-Speed. Selain itu, dengan memanfaatkan fasilitas IoT di mikrokontroller, diharapkan sistem dapat mengakses peralatan elektronik dengan teknologi lama dan entry level secara wireless melalui WiFi.

\section{Daftar Rujukan}

[1] T. Darmanto and H. Krisma, "Implementasi Teknologi IOT Untuk Pengontrolan Peralatan Elektronik Rumah Tangga Berbasis Android," J. Tek. Inform. Unika St. Thomas, vol. 04, pp. 1-12, 2019.

2] R. Susana, M. Ichwan, and S. A. L. Phard, "Penerapan Metoda Serial Peripheral Interface ( SPI ) pada Rancang Bangun Data Logger berbasis SD card," J. Elkomika, vol. 4, no. 2, pp. 208-227, 2016.

[3] A. Astudillo, P. Munoz, F. Alvarez, and E. Rosero, "Altitude and Attitude Cascade Controller for a Smartphone-based Quadcopter," in 2017 International Conference on Unmanned Aircraft Systems, ICUAS 2017, 2017, pp. 1447-1454, doi: 10.1109/ICUAS.2017.7991400.

4] X. Li, H. Yu, Y. Yew, H. Liu, and M. Hong, "A Portable Optical Sensing System for Rapid Detection of Fluorescence Spectra," Guangdian Gongcheng/Opto-Electronic Eng., vol. 44, no. 5, pp. 483-487, 2017, doi: 10.3969/j.issn.1003-501X.2017.05.002.

[5] M. Iqbal, T. W. Widodo, and B. A. A. Sumbodo, "Sistem Pengendali Pengambilan Gambar Pada Kamera DSLR Melalui Protokol PTP 1," IJEIS, vol. 6, no. 2, pp. 117-128, 2016.

[6] A. Novriadi, "Perancangan Pengontrolan Overhead Crane Menggunakan Kabel dan Nirkabel Berbasis Arduino sangat banyak ditemukan di berbagai dunia bekerja mengangkut bahan material Agar terhindarnya dari kecelakaan penggunaan yang digunakan adalah Joystick PlayStation3 Ar," J. Teknol. Terpadu, vol. 7, no. 2, pp. 76-84, 2019.

7] E. Systems, "ESP32 Series Datasheet," 2021.

[8] I. Circuits, "Data sheet," no. September 1993, 1998.

[9] P. Dhaker, "Introduction to SPI Interface," Analog Dialogue, no. September. pp. 1-5, 2018, [Online]. Available: https:/www.analog.com/media/en/analog-dialogue/volume52/number-3/introduction-to-spi-interface.pdf.

[10]U. S. B. D. States and V. D. States, "Chapter 9 USB Device Framework," in Universal Serial Bus Specification Revision 2.0, pp. 239-274. 